\title{
Implementing A New Style of Learning in A Taught Postgraduate Medical Ultrasound Programme: Reflections on the First Year
}

Vivien Gibbs \& Julie Hobbs

Health \& Life Sciences, University of the West of England, Glenside Campus, Stapleton, Bristol, BS16 1DD, UK

\begin{abstract}
The successful introduction of an action based learning (ABL) module into the medical ultrasound programme several years ago, has led to further developments using this approach. Conflicting pressures from hospital departments requesting increasing numbers of subject specialty areas to be taught, and university managers requiring modules to be economically viable, resulted in a more creative approach to delivery of the programme. $A B L$ requires students to take responsibility for their own learning, thereby promoting independent learning. This is generally recognised as a more effective method for acquiring knowledge and skills, particularly at postgraduate level. Following completion of the first year of this newly accredited module, the experiences of students and staff were evaluated. Results of the evaluation and feedback demonstrated that students initially struggle to understand the concept of ABL. However, results of student assessments showed that once individuals engage with the process, knowledge and skills can be successfully acquired, demonstrating that this style of learning is a tool which can be potentially used in many aspects of life.
\end{abstract}

Keywords: Action Based Learning, Independent Learning, Learning Tools, Postgraduate Courses

\section{Introduction}

This article relates to the MSc programme in medical ultrasound developed and delivered at the University of the West of England (UWE). The students on the programme are all mature employed healthcare workers studying part-time for a Postgraduate Certificate, Postgraduate Diploma or Master of Science award

A new style of learning was introduced into the programme five years ago. The subsequent success of this has led to further developments within the programme over the past year, to widen access to a greater number of students. The experiences of students and staff following the first year of delivery of this new programme, are reviewed in this article.

\section{Background}

UWE has been delivering a postgraduate medical ultrasound programme since 2000, and in 2003 introduced a new module named Negotiated Specialist Practice in medical ultrasound. The module was structured around an action based learning $(\mathrm{ABL})$ style of delivery, which is a tool for facilitating learning, specifically in linking theoretical knowledge to the practical workplace setting. ${ }^{1}$ It involves a process whereby students take control of their own learning, using advice and guidance from fellow students and a personal tutor. The module was validated as a second year 40 credit module which students could choose from a selection of professional practice modules. The rationale for limiting the negotiated specialist practice module to the second year was to enable students to select an area of advanced practice, building on the subject

Correspondence: Vivien Jane Gibbs, Health \& Life Sciences, University of the West of England, Glenside Campus, Stapleton, Bristol, BS16 1DD, UK. vivien.gibbs@uwe.ac.uk

Ultrasound 2009:17(2):85-89

(c) British Medical Ultrasound Society 2009 knowledge obtained in the first year. It was perceived that students would need to have some knowledge of the subject in order to enable appropriate progression through the module.

When the programme was due for revalidation and reaccreditation in 2007, the course team was aware of the conflicting demands from the University to only run modules with a minimum of 20 students, and the demands for training from hospital departments needing to expand their range of ultrasound services by diversifying into an increasing number of sub-specialty areas. Requests were being received from departments wishing to train staff in a number of specialty areas such as breast, paediatric, and musculoskeletal, which would have resulted in a number of new modules having to be created, each of which would probably have less than four students enrolled. During discussions between University staff and stakeholders, it became apparent that the solution was to extend the role of the negotiated specialist practice module by offering it as either a first or second year module to enable students to study a defined area of ultrasound even though they may not have had previous clinical experience of that particular area of study. This solution would have the additional benefit of requiring students to take control of their own learning process rather than being a passive recipient of knowledge delivered by others. ${ }^{2}$ This is considered a more effective method of learning, particularly at postgraduate level. ${ }^{3}$ Some concern was initially expressed that, without any prior knowledge of the subject, students would struggle with the $A B L$ process. However, it was felt that the nature of $\mathrm{ABL}$ as a facilitative tool for learning, is appropriate for $\mathrm{M}$ level learners as it enables them to enhance autonomous approaches to study, whilst still receiving support from academics and peers.

The programme was successfully validated and accredited in October 2007 and the first students were recruited to the programme in January 2008. Students now have the option to study a 20 credit module over six months, or a 40 credit module over 12 months. The size of the module chosen is determined by the size of the subject specialty area studied, and the decision involves a discussion between the student 
and module team. Assessment of the module is identical to assessments on the other UWE professional practice modules, namely a practical clinical assessment, a viva voce, completion of a clinical portfolio and a written assignment. In addition students are also required to write a reflective article on the $\mathrm{ABL}$ process and its application to their own learning.

\section{Action based learning}

The Negotiated Specialist Practice module is delivered using an $\mathrm{ABL}$ format whereby students are facilitated by an experienced $\mathrm{ABL}$ practitioner. $\mathrm{ABL}$ was originally described by Revans ${ }^{4}$ as a process whereby managers from different factories, unknown to each other, could meet in small groups to discuss and reflect on work-based problems they were experiencing. The aim was to develop their knowledge and ability to manage in a variety of settings. The process has subsequently been adapted for use in education to promote independent learning, by encouraging students to develop knowledge and abilities specific to individual student needs. ${ }^{5}$

The ABL process consists of a number of students who meet together regularly to present problems to their peers in order to find ways to overcome them. This is known as a "learning set', and is differentiated from a team because the focus is very much on the individual. ${ }^{4}$ Whereas a team has a welldefined group task, the ABL set works for each individual, by helping to define future actions of each set member. ${ }^{6}$

During the set meeting, each student is given 'air space' which is the opportunity to present problems/issues to the set as a whole. ${ }^{7}$ The role of the other set members at this point is to listen and support the student in moving forward with the problem or issue. This process needs to be objective, and a challenging approach may be necessary. Students new to the process usually require help to develop the requisite skills, hence the involvement of a facilitator is obligatory. ${ }^{8}$ Furthermore, in order to ensure every student has the opportunity to present a problem or issue, firm time constraints are necessary. Minutes of the meeting are also required, in order to record agreed action points to be used as items of reference for the next meeting. Students are required to keep a reflective diary to record action points and any progress made with them.

Learners are required to write their own learning objectives (LOs) at the start of the course, and identify (in negotiation with the module leader) how each of these LOs will be assessed within the framework of the module. Students attend the University approximately one day every three weeks and spend the first two hours of the day working in small groups, identifying problems encountered with their learning process, either theoretical or practical. Students in each group may be studying different specialty areas of ultrasound, and may have different healthcare backgrounds. This diversity of experience within the group results in interesting discussions and viewpoints on how each student can best tackle their particular problem. An additional benefit is that a variety of students from differing professional backgrounds can work together and all benefit from this multi-professional interaction.
During the day of attendance at UWE, students have a certain number of subject specific lectures and workshops. Six lecturers are involved with the module, acting as both facilitators for the learning sets and as personal tutors. Each student has individual access to their tutor, but in addition they can contact their tutor at any time during the month via email or telephone. Module leaders post information on an electronic noticeboard which students can access off-site. Despite some structured theoretical sessions, the concern is often that students feel they are teaching themselves. However, this is not a weakness of the $A B L$ process, but rather its strength as it promotes independent learning. ${ }^{9}$

This style of learning is a difficult concept for students beginning the module. Students struggle to make sense of $\mathrm{ABL}$ initially, and clearly are often placed outside of their 'comfort zones'. Requests were made at the beginning of the module for a more didactic style of learning, where students could sit in a classroom and be delivered knowledge in the form of a lecture with slides and handouts. However, it was observed that as the module progressed, students began to realise what was expected of them and move away from the traditional expectations they originally began with.

\section{Evaluation of the ABL process}

\section{Methodology}

Following the delivery of the first year of the modules to 34 students, the module leaders distributed a standard university evaluation form, plus an additional questionnaire (see Appendix). This questionnaire was posted to all students with a pre-paid return envelope, and results collated. Questions on the form were a combination of closed and open-ended, in order to elicit focused and constructive feedback. The questionnaire was designed to be straightforward to complete, to encourage a good completion rate. Students were strongly encouraged to return forms in order to provide the course team with information to improve the module for future intakes. Twenty-six forms were returned in total, giving a $76 \%$ response rate.

The module team was composed of six lecturers, and this team met at the end of the module to feedback and discuss their views on the strengths and weaknesses of the module. Student responses were also reviewed at this meeting.

\section{Results}

Student feedback revealed mixed attitudes to this style of learning. Table 1 demonstrates responses to the questions. Whilst the majority of students did eventually appreciate the relevance of $A B L$ to the learning process there remained two respondents who never achieved this. Eight of the students revealed that their knowledge of the $A B L$ process was not sound, and seven thought that there should have been more subject specific content. Four students had problems with the self-study aspect of the module and this was expanded upon in the comments sections.

Comments from students were varied but revealing:

Table 1. Student evaluation responses

\begin{tabular}{lrr}
\hline Question & No \\
\hline Having engaged with the ABL process, do you appreciate its relevance to this work based learning module? & Yes \\
Do you think that you have obtained a sound knowledge base with regard to the ABL process? & 24 & 18 \\
Did the module have enough subject specific theoretical content? & 19 & \\
Did you have problems engaging with the self-study aspects of this module? & \\
\hline
\end{tabular}


- twelve students expressed a preference for a more traditional style of learning, and although lectures and on-line learning material were provided for all students in their different sub-specialty areas, many would have preferred more;

- two students expressed irritation with $\mathrm{ABL}$ as a learning tool and felt their time would have been more profitably used by attending lectures;

- three students felt that they never really understood the process until nearer the end of the module. When questioned, they admitted that they had performed little, if any, background reading on the subject until they came to write their reflective essay on the $A B L$ process at the end of the module;

- the majority of students commented that they found the $A B L$ concept challenging initially, however, they did eventually realise the benefits that the process had brought them;

- the support received from fellow students in the learning sets had been a powerful tool for many students:

- five students commented that, as a result of discussions in the learning sets, they had managed to obtain sound advice from their fellow students to help them overcome problems with both the clinical placement and the academic study;

- three students managed to organise visits to fellow students' departments to obtain additional clinical experience;

- two students admitted that they would have left the course, due to problems with their clinical placements, if it had not been for the supportive advice and practical help received from others in the learning set;

- six students commented that this style of learning enabled them to work at their own pace, with the ABL providing a framework to give them support;

- four students admitted that they encountered problems with the self-study aspect of the module. They would have preferred more structure to their learning, with deadlines to work to, because most of their studying was postponed until towards the end of the module;

- three students commented that they would have found the learning sets more effective if they had included students studying similar subject areas, rather that the multi-professional mix that had been used. When initially planning the module it was felt by the course team that students would benefit more from the multiprofessional opportunities that they would be exposed to by being within mixed learning sets, however, a different approach is planned for the next cohort of students;

- four students would have preferred to spend more time working on particular subject related tasks within their learning sets, in order to focus their learning around a particular facilitator-led topic.

The experience of the module team in the first year of delivery of the Negotiated Specialist Practice module has been enlightening. Staff comments included the following:

- more time needs to be spent at the beginning of the module facilitating students in the understanding of how to learn:

- students need greater encouragement to research the $\mathrm{ABL}$ mechanism at the beginning of the module to ensure a greater understanding of the process;
- it was often difficult to hold students' attention in the learning sets when problems were being discussed which were not perceived as being something the entire group could empathise with. This was probably a result of the multi-professional nature of the groups;

- the learning sets often required more than the allotted $1.5 \mathrm{~h}$. This was due to the numbers of students within each of the learning sets. Group sizes consisted of nine students in two of the sets and eight in the other two. They were larger than the recommended maximum (Revans recommends a maximum of six) ${ }^{4}$ due to an unexpectedly large recruitment of students to the modules:

- overall the course team were impressed with the levels of knowledge and understanding demonstrated by students in their final assessments;

- some students, particularly those in their first year of studies, appeared to struggle initially with using elearning facilities, and this may have disadvantaged them when trying to access information for the module. Although study skills sessions are offered to students at the start of the course, uptake is not always good, due to a number of reasons. Many do not like to admit to weaknesses and assume they will learn as they proceed through the programme. The blended learning approach involved in this Negotiated Specialist Practice module means that any information technology (IT) weaknesses can become a real barrier to learning, and staff were aware that this appeared to be a problem for a minority of students.

Overcoming initial student resistance has been a feature of the module, and methods for countering this have been put in place for the new intake. At the end of the first year of delivery of this programme, final assessment results have been good, with an $80 \%$ pass rate. Those students who successfully completed the module have demonstrated that they clearly invested much time and energy in acquiring new skills and knowledge. It has been rewarding for staff to observe the development of these students as they progress through the module and become more autonomous in their learning.

\section{Limitations}

The module leaders realised it was important to obtain indepth evaluation from the staff and students of this new module following completion of the first year of delivery. It is planned to deliver the module again, but modifications will be made incorporating the feedback from staff and students. Numbers of students completing evaluation on this first module provided a limited amount of information to determine any statistical trends, however the feedback from students is valuable and can be used to enhance next year's module.

It is planned to extend the research following completion of the next cohort. Specific factors influencing successful or unsuccessful outcomes for students will be explored, such as the particular specialty the respondents were studying, the number of hours of face-to-face delivery they received, attendance rates and the support received in practice.

\section{Recommendations for future module runs}

- Numbers for the learning sets will be limited to a maximum of six.

- Students will be placed in groups divided into subject specialties.

- More emphasis will be placed on the acquisition of appropriate IT skills at the beginning of the module. 
- Pre-course reading on the $\mathrm{ABL}$ process will be mandatory, and more time will be spent discussing the process of $A B L$ on the first day of the module.

\section{Discussion}

\section{The need for independent learning in postgraduate programmes}

Within the healthcare professions there has been a move away from formal classroom learning towards a more clinically based style of evidence based learning. Marshall ${ }^{10}$ observes additionally that in a profession such as diagnostic imaging, where modern technology is constantly changing, and staff typically progress through many roles, it is important that they have learnt how to be independent in their learning. The requirement for documented evidence of continuing professional development (CPD) ${ }^{11}$ in order to retain professional registration, puts additional emphasis on the ability of professionals to be able to learn throughout their careers.

Learning, however, only takes place when individuals take responsibility for learning and actively seek to develop themselves. ${ }^{12}$ Independent learning focuses on the creation of the opportunities and experiences necessary for learners to become capable, self-reliant, self-motivated, life-long learners. $^{13}$ There needs to be meaningful learning activities to enable learners to take responsibility for their own learning, and it is the role of the teacher to act as a facilitator to enable this to happen ${ }^{14}$

Joyce ${ }^{15}$ argues that there should be a level of discomfort in the learning process, and that significant learning will only take place if the student is placed in an uncomfortable environment. By this he means that if the environment and the student are too much in harmony, the student is permitted to operate at a level of comfort that does not require the challenge of growth. Independent learning can often provide this uncomfortable stimulus, by encouraging students to take control of their own learning.

It is generally accepted that at postgraduate level a learnercentred approach is a more effective method for acquiring knowledge and skills. ${ }^{10}$ However this is often overlooked when designing the curriculum and assessments for a course. ${ }^{16}$ Learning at postgraduate level is usually complex, and as individuals each have their own preferred learning style, ${ }^{17}$ any formal didactic approach to the teaching will often not prove to be effective for all students. ${ }^{3}$ In order to support independent learning, students need to learn how to learn ${ }^{12}$ and once they have grasped this concept, it will be a tool that can be used in all aspects of life. These skills can be effectively facilitated if embedded within a particular field of study ${ }^{18}$ where they can be applied to real-life scenarios.

\section{The application of $A B L$ as an independent learning tool}

Any student embarking on a programme of study needs to remember that whatever is to be learned must be learned by the student, and that active participation has to take place in the learning rather than passive listening. Knowles ${ }^{13}$ says that the learner has to take the initiative and be proactive in any learning process. Training programmes therefore need to engender a sense of ownership and responsibility within the student. $^{19}$

Understanding the learning process is one way to improve the ability to learn. Kolb ${ }^{20}$ described the circular process of learning (see Fig 1), where the key stages are Experience, Reflection (or reviewing the experience), Theorising (or concluding from the experience) and Experimentation (planning the next stage). This learning process has been used as

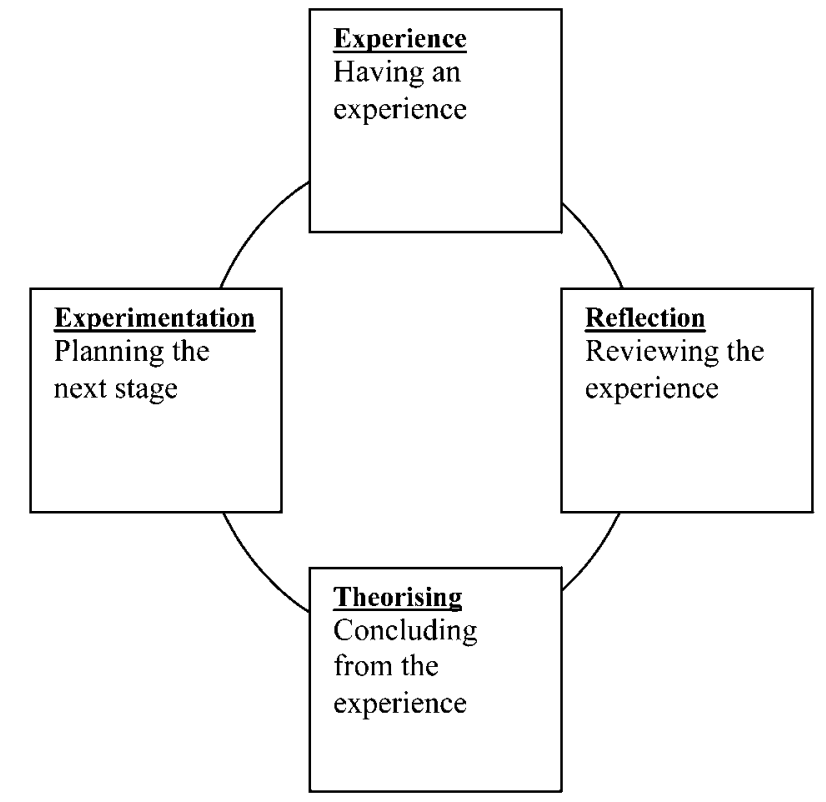

Figure 1. Kolb's learning cycle. ${ }^{20}$

the fundamental core of $A B L$, where students are first required to reflect on their sphere of practice (Reflection). They develop an awareness of the problems that need to be presented to their learning set and use the opportunity to discuss the problems with others in the set (Theorising). This process of discussion within an empathetic, supportive group provides a new dimension for reflection on the problem (Experimentation). Gradually an action plan is developed and implemented (Experience). Opportunities for review of the action takes place at subsequent set meetings. Whilst reflection may often be seen as a discrete process, ${ }^{21} \mathrm{ABL}$ uses reflective processes as spiral progression to ensure the agreed learning outcomes are met. If used correctly, ABL can be a powerful tool to promote independent learning in individuals.

\section{Conclusions}

At any stage of life, the ability to learn is fundamental to future development. The requirement for documented evidence of $\mathrm{CPD}$ in the healthcare professions means that no individual can afford to stop learning. Whilst many individuals still equate the learning process with sitting in a classroom being spoonfed information, this didactic form of teaching is often being replaced with techniques considered to be more effective in promoting learning. Significant learning only takes place when individuals accept responsibility for their own learning, and actively seek to develop themselves. Programme leaders need to ensure they facilitate opportunities for the learner to be proactive in the learning process.

The diversification of medical ultrasound into numerous subject areas puts pressure on providers of postgraduate education to deliver programmes with an ever increasing number of subject specific modules. In the current economic climate this is not a sustainable method for educating the workforce, and alternative approaches need to be found.

If used appropriately, the integration of Action Based Learning is a useful mechanism to successfully address both these requirements. It not only enables students studying a variety of subject areas to study together in larger groups, but also relies on students taking responsibility for their own learning, to ensure the learning is deeper and more effective. Once students have grasped the concept of Independent 
Learning, it becomes a tool that can be used in many aspects of life to acquire new skills and knowledge.

\section{References}

1. Johnson C. The essential principles of action learning. $J$ Workplace Learn 1998;10(6/7):296-300.

2. Candy PC. Self-direction on life-long learning, higher and adult education series. San Francisco, CA: Jossey Bass, 1991.

3. Khan K, Pakkal M. Formal structured teaching in postgraduate training: a learner centred educational programme. Hosp Med 2002;63(12):764-769.

4. Revans R. Action learning: new techniques for action learning London: Blond and Briggs, 1980.

5. Pedler M. Action learning in practice. 3rd edn. Aldershot: Gower Publishing, 1997.

6. McGill I, Beaty L. Action learning: a guide for professiona management and education. London: Routledge, 2001.

7. Revans R. The ABC of action learning. Bromley, Kent: Chartwell Bratt, 1983.

8. Colliver J. Effectiveness of problem-based learning curricula: research and theory. Acad Med 2000;75(3):259-266.

9. Marquardt M. Harnessing the power of action learning. Train Devel 2004;58:26-32.

10. Marshall G. Promoting learning by curriculum design and assessment in a taught postgraduate MRI programme. Radiography 2008;14:238-245.

11. Simon F, Aschenbrener C. Undergraduate medical education as a driver of lifelong learning. J Cont Educ Health Prof 2005;25(3):157-161.

12. Gibbs V. Learning how to learn: a selective review of the literature. Radiography 2000;6:231-235.

13. Cotton J. Understanding and thinking. in: The theory of learning London: Kogan Page, 1995;128-129.

14. Fry $\mathrm{H}$, Ketteridge S, Marshall S. A handbook for teaching and learning in higher education. London: Routledge Falmer, 2003.

15. Joyce BR. Dynamic disequilibrium: the intelligence of growth. Theory Pract 1984;23(1):26-34.

16. Biggs JB. Approaches to the enhancement of university teaching. Higher Educ Res Devel 1989;22:7-25.

17. Honey $\mathrm{P}$, Mumford A. Setting the scene for learning styles. in: The manual of learning styles, 5-7. Maidenhead: Honey, 1992

18. Stark S. Using action learning for professional development. Educ Act Res 2006;14(1):23-43.

19. Cotton J. Motivation and goal clarity. in: The theory of learning, 64-67. London: Kogan Page, 1995.
20. Kolb D. Experiential learning experience as the source of learning and development. London: Prentice Hall, 1984

21. Boyd FM, Fales AW. Reflective learning: key to learning from experience. J Human Psychol, 1983:23(2):99-117.

\section{Appendix}

\section{Medical ultrasound programme evaluation of the negotiated specialist ultrasound practice module}

Following completion of the first cohort of students through this new module, the course team would be grateful for feedback from the students in order to help us improve the module for future students.

Having engaged with the ABL process, do you appreciate its relevance to this work based learning module?

Yes/No

If not, please can you identify the reasons for answering no?

Do you think that you have obtained a sound knowledge base with regard to the $A B L$ process?

Yes/No

If not what are the reasons for this?

Did the module have enough subject specific theoretical content?

Yes/No

If this was not the case please specify the areas for development

Did you have problems engaging with the self-study aspects of this module?

Yes/No

If yes, what do you consider to be the reasons for this?

How do you feel the ABL process can be made more appropriate for the delivery of this ultrasound module?

Do you have any ideas on how the learning and assessment on the module can be improved? 